\title{
Increased Conversion Ratio of Tryptophan to Niacin by Dietary Di-n-butylphthalate
}

\author{
Katsumi Shibata, Tsutomu Fukuwatari, Ai Enomoto and Etsuro Sugimoto \\ Course of Food Science and Nutrition, Department of Life Studies, School of Human Cultures, \\ The University of Shiga Prefecture, 2500 Hassakacho, Hikone, Shiga 522-8533, Japan
}

(Received January 16, 2001)

\begin{abstract}
Summary We reported that the growth promoting activity of di-n-butylphthalate (DBP) was observed when rats were fed with a niacin-free and tryptophan-limiting diet (Shibata et al., 1982. J Nutr Sci Vitaminol 28, 173-177). The present experiment was performed to investigate whether this phenomenon is attributable to the increase in the conversion ratio of tryptophan to niacin. The weaning rats were fed with a $10 \%$ (low protein diet) or $20 \%$ protein (conventional protein diet) diet with or without adding $1 \%$ DBP. The conversion ratio of tryptophan to niacin was significantly higher in the DBP group than in the control group; for $10 \%$ casein diets, it increased two-fold and for $20 \%$ casein diet, about five-fold. From these results, the previous finding is possibly explained by DBP increasing the conversion ratio of tryptophan to niacin.
\end{abstract}

Key Words tryptophan metabolism, niacin, di- $n$-butylphthalate

Phthalic acid has been reported to be a strong competitive inhibitor of QPRT (EC 2.4.2.19), which is the rate-limiting enzyme in the Trp-niacin pathway (1), in animals (2-4) and bacteria (5). DBP is a constituent of such diverse products as paints, adhesives, cosmetics and polyvinyl-chloride plastics (6). These esters are widely distributed throughout the environment and have been detected in animals and humans (7). A part of the DBP is hydrolyzed into phthalic acid $(8,9)$. If niacin and Trp intakes are low, the intake of DBP may accelerate the development of niacin-deficiency.

Shibata et al. (10) reported that the growth promoting activity by DBP was observed when rats were fed a niacin-free and Trp-limiting diet and that it is not clear why the administration of DBP has resulted in the growth promoting activity for weaning rats fed the niacin-free diet. They suggested that the conversion of Trp to niacin was promoted by the DBP intake (10). However, it is possible that this phenomenon is limited only when rats were fed the niacin-deficient diet. Recently, Chang and Zylstra et al. (11) reported that some microorganisms induced QPRT by phthalic acid esters. We investigated the effect of DBP on the conversion ratio of Trp to niacin in rats and on the activity of QPRT when rats were fed 10\% (low protein diet) and $20 \%$ protein diets (conventional protein diet) because the conversion ratio is affected by dietary protein levels (12).

Vitamin-free milk casein, sucrose, L-methionine, and

Abbreviations: QPRT, quinolinate phosphoribosyltransferase; Trp, tryptophan; DBP, di- $n$-butylphthalate; Nam, nicotinamide; MNA, $N^{1}$-methylnicotinamide; 2-Py, $N^{1}$-methyl-2pyridone-5-carboxamide; 4-Py, $N^{1}$-methyl-4-pyridone-3-carboxamide.
Nam were purchased from Wako Pure Chemical Industries (Osaka, Japan). MNA chloride was obtained from Tokyo Kasei Kogyo (Tokyo, Japan). 2-Py and 4-Py were synthesized by the methods of Pullman and Colowick (13) and of Shibata et al., (14) respectively. The mineral and vitamin mixtures were obtained from Oriental Yeast Kogyo (Tokyo, Japan), all other chemicals used being of the highest purity available from commercial sources.

The animal room was maintained at a temperature of around $22^{\circ} \mathrm{C}$ and at about $60 \%$ humidity with a $12-\mathrm{h}$ light/12-h dark cycle. Body weight and food intake were measured daily at around 10:00 a.m., and food and water were freely fed and renewed daily.

The care and treatment of the experimental animals conformed to The University of Shiga Prefecture guidelines for the ethical treatment of laboratory animals. Male rats of the Wistar strain (3-wk old) were obtained from CLEA Japan (Tokyo, Japan) and immediately placed in individual metabolic cages (CT-10; CLEA Japan). They were then divided into four groups, and fed ad libitum for $32 \mathrm{~d}$, in a low-protein diet experiment, one group with a niacin-free, $10 \%$ casein diet and the other with the same diet $+1.0 \%$ DBP (Table 1 ), and in a conventional protein diet experiment, one group with a niacin-free, $20 \%$ casein diet and the other with the same diet $+1.0 \%$ DBP (Table 1). Urine samples (10:00 a.m.-10:00 a.m.; 24-h urine) were periodically collected in amber bottles with $1 \mathrm{~mL}$ of $1 \mathrm{M} \mathrm{HCl}$ and stored at $-25^{\circ} \mathrm{C}$ until needed. The rats were killed by decapitation after the last urine samples had been collected. The liver of each animal was removed, and a portion (approximately $1 \mathrm{~g}$ ) was immediately homogenized with a Teflon-glass homogenizer in five volumes of a cold $50 \mathrm{~mm} \mathrm{KH} \mathrm{PO}_{4}-\mathrm{K}_{2} \mathrm{HPO}_{4}$ buffer $(\mathrm{pH}$ 7.0). One part of 
Table 1. Composition of the diets.

\begin{tabular}{lcccc}
\hline & $\begin{array}{c}10 \% \text { Casein diet } \\
(\%)\end{array}$ & $\begin{array}{c}10 \% \text { Casein diet } \\
+1 \% \text { DBP }(\%)\end{array}$ & $\begin{array}{c}20 \% \text { Casein diet } \\
(\%)\end{array}$ & $\begin{array}{c}20 \% \text { Casein diet } \\
+1 \% \text { DBP }(\%)\end{array}$ \\
\hline Vitamin-free casein & 10 & 10 & 20 & 20 \\
L-Methionine & 0.1 & 0.1 & 0.2 & 0.2 \\
Gelatinized cornstarach & 50.95 & 50.45 & 45.9 & 45.4 \\
Sucrose & 27.95 & 27.45 & 22.9 & 5 \\
Corn oil & 5 & 5 & 5 & 5 \\
Mineral mixture* & 5 & 5 & 1 & 1 \\
Vitamin mixture (niacin-free) & 1 & 1 & 0 & 1 \\
DBP** & 0 & 1 & 5 & 1 \\
\hline
\end{tabular}

* The compositions of the mineral and vitamin mixtures are described in the following reference: Shibata K, Matsuo H. 1989. Effect of supplementing low protein diets with the limiting amino acids on the excretion of $N^{1}$-methylnicotinamide and its pyridones in rats. J Nutr 119: 896-901. ** Niacin-free means that nicotinic acid is removed from the vitamin mixture. ${ }^{* * *} \mathrm{DBP}=$ di- $n$-butylphthalate.

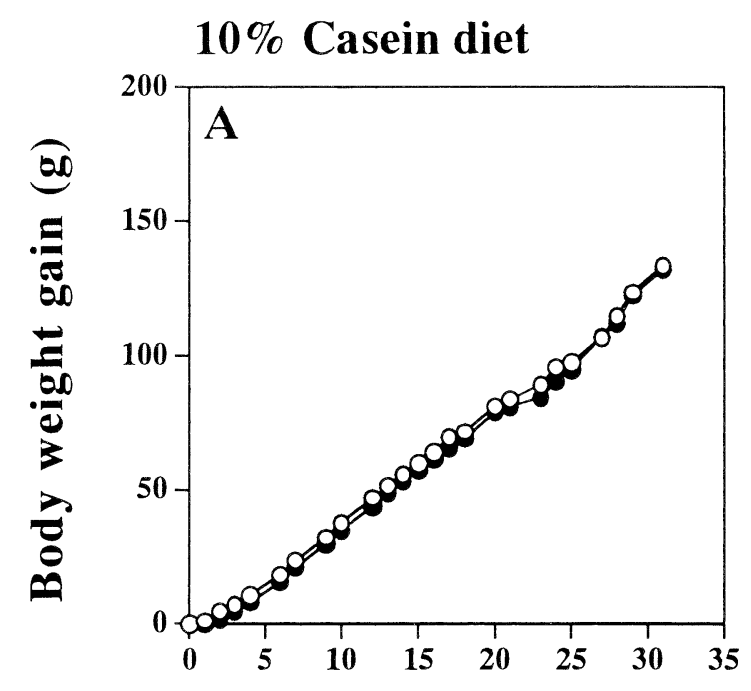

(d)

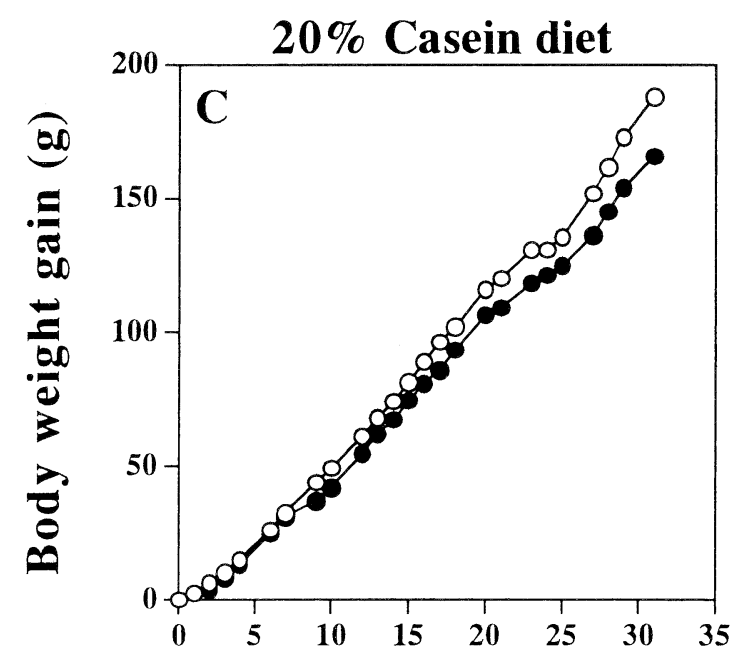

(d)

\section{$10 \%$ Casein diet}

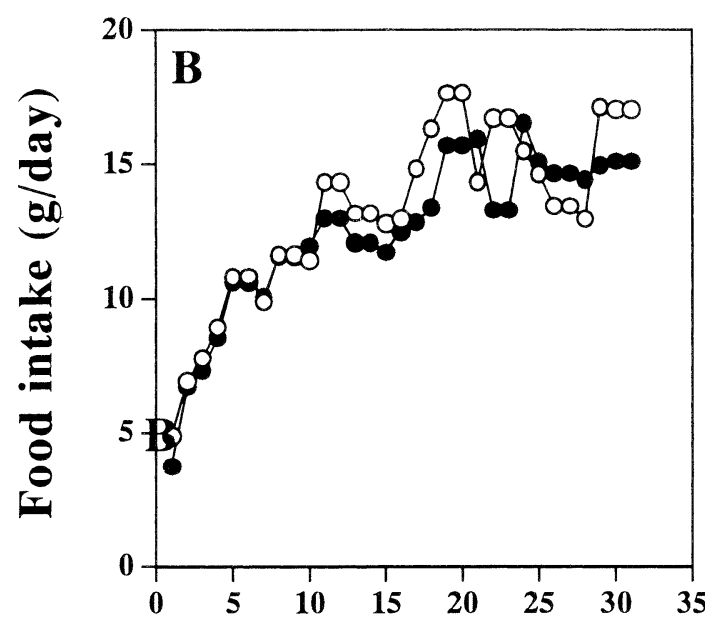

(d)

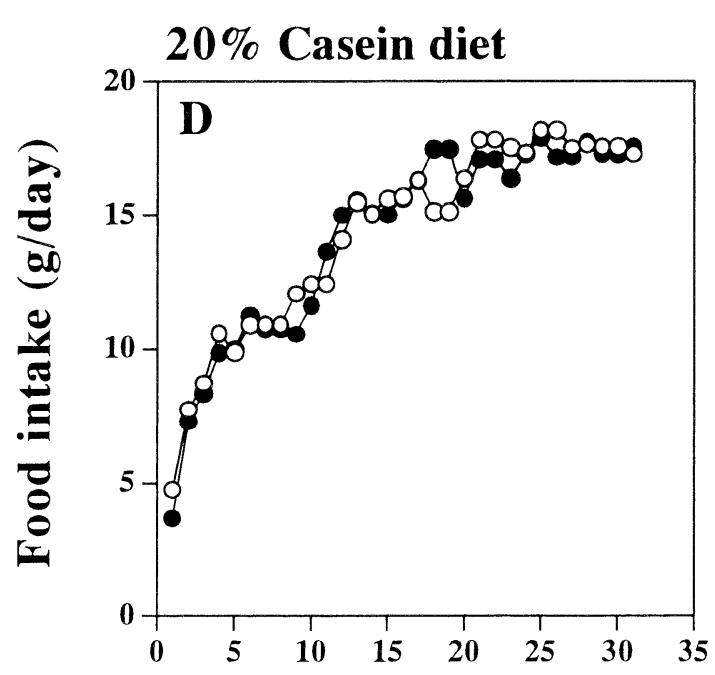

(d)

Fig. 1. Effects of dietary DBP on the body weight gain (A, C) and food intake (B, D) of weaning rats fed with a $10 \%$ casein diet and a $20 \%$ casein diet. $\bigcirc$, control; $\bullet$, DBP. each point is mean for 5 rats. 
each homogenate was centrifuged at $105,000 \times g$ for 20 min to measure the activity of QPRT.

The activity of QPRT was measured as described in the literature (15). The contents of Nam, 2-Py, and 4-

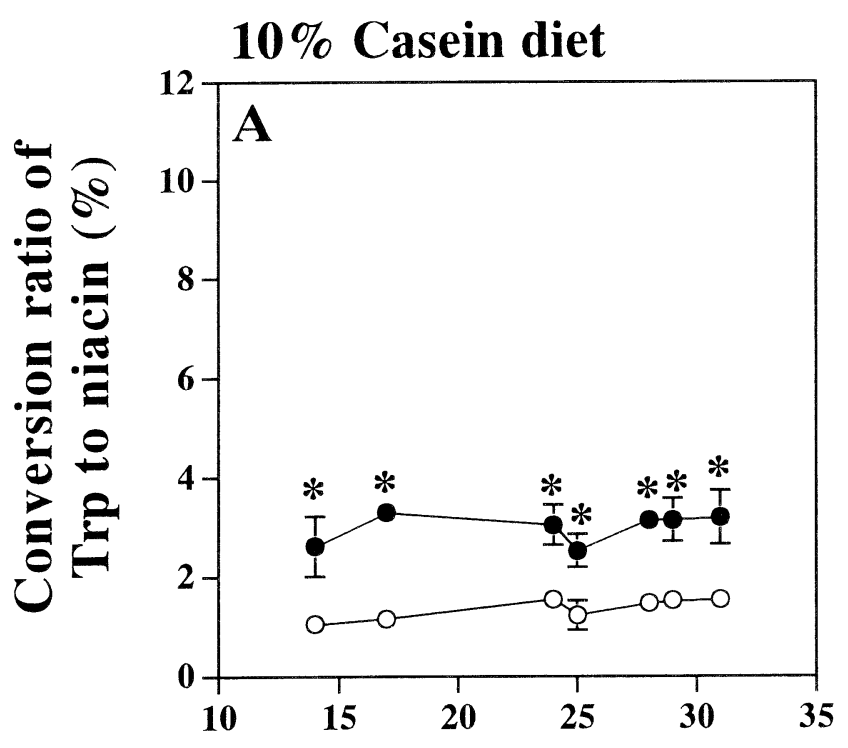

(d)

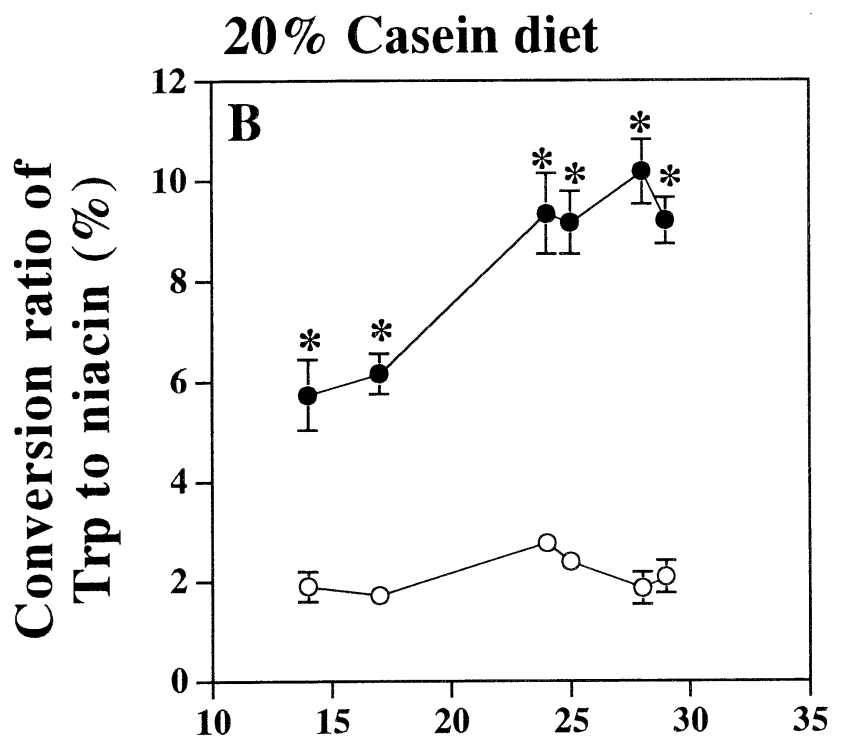

(d)

Fig. 2. Effects of Dietary DBP on the Conversion Ratio of Trp to Niacin of Rats Fed with a 10\% Casein Diet (A) and a 20\% Casein Diet (B). O, control; - DBP. Each point is mean \pm SE for 5 rats. *, Significantly different at $p<0.05$ on the same day, as determined by Student's $t$-test.
Py in the urine were simultaneously measured by the HPLC method of Shibata et al., (14) while the content of MNA in the urine was measured by the HPLC method of Shibata (16).

The addition of DBP to the niacin-free and $10 \%$ casein diet did not affect the body weight gain or food intake of weaning rats for $32 \mathrm{~d}$ as shown in Fig. 1-A and $-B$, nor did the addition of DBP to the niacin-free and 20\% casein diet, as shown in Fig. 1-C and -D. These results mean that the toxicity of DBP did not appear under these conditions. In the present experiment, niacin-free diets were used, but the rats did not seem to be niacin-deficient for a sufficient amount of niacin could be supplied from Trp in casein.

To determine the conversion ratio of Trp to niacin, the urinary outputs of Nam, MNA, 2-Py, and 4-Py were measured, all of which were derived from Trp since the diets were niacin-free. The urinary outputs of Nam, MNA, 2-Py, and 4-Py were significantly increased in the groups with the $10 \%$ and $20 \%$ protein diets by DBP intake (data not shown). The conversion ratio was calculated as the sum of the urinary outputs of Nam+ $\mathrm{MNA}+2-\mathrm{Py}+4-\mathrm{Py}(\mu \mathrm{mol} / \mathrm{d}) \times 100 /$ Trp intake during urine collection $(\mu \mathrm{mol} / \mathrm{d})$. Figure $2-\mathrm{A}$ shows the effect of DBP on the conversion ratio of Trp to niacin. The DBP addition to the $10 \%$ diet gave a two-fold increase in the conversion. Furthermore the addition of DBP to the $20 \%$ casein diet gave a five-fold increase in the conversion as shown in Fig. 2-B. Therefore, it seemed that DBP activated the conversion pathway of Trp to niacin. However, another explanation might be possible, because Walseth et al. (17) reported that a significant decrease in the serum level of albumin was observed after treatment with DBP. The decrease in serum albumin might cause an increase in free Trp, which is absorbed by liver and is converted to niacin. In other words, DBP might increase available Trp due to decrease in serum albumin. The difference of the scale of increase between the groups of the $10 \%$ and $20 \%$ protein diets could be attributed to the difference of Trp intake (12). From these results, the previous finding that the growth promoting activity by DBP was observed when rats were fed with the niacin-free and Trp-limiting diet (10), is possibly explained by the fact that DBP increased the niacin supply from Trp, namely the conversion ratio of Trp to niacin.

Table 2 shows the effect of DBP on the liver QPRT activity. The activity did not change with the addition of DBP in the $10 \%$ casein and 20\% casein diets, although phthalic acid, a hydrolysis product of DBP, is an inhibitor of QPRT (2-5). This result means that the con-

Table 2. Effect of dietary DBP on liver QPRT activity.

\begin{tabular}{ccccc}
\hline 10\% Casein diet & $\begin{array}{c}10 \% \text { Casein diet } \\
+1 \% \text { DBP }\end{array}$ & $20 \%$ Casein diet & $\begin{array}{c}20 \% \text { Casein diet } \\
+1 \% \text { DBP }\end{array}$ \\
\hline QPRT & $909 \pm 33$ & $937 \pm 11$ & $854 \pm 37$ & $825 \pm 38$ \\
\hline
\end{tabular}

Each value is expressed as $\mathrm{nmol} / \mathrm{h} / \mathrm{g}$ of liver and is the mean $\pm \mathrm{SE}$ for 5 rats. 
centration of phthalic acid did not reach the threshold of the inhibition of QPRT activity. On the contrary, it was reported that QPRT from some microorganisms was induced by DBP (11). But, QPRT from rats could not be induced by DBP.

In summary, the present experiments showed that DBP increased the urinary outputs of Nam, MNA, 2-Py, and 4-Py. In other words, it is probable that DBP activated the conversion pathway of Trp to niacin. Liver QPRT was not induced by the administration of DBP. The mechanism by which phthalic acid ester increases the conversion of Trp to niacin is unknown and needs to be made clear.

\section{Acknowledgment}

This investigation was supported in part by a grant from The USP Foundation for Academic and Cultural Promotion.

\section{REFERENCE}

1) Ghafoorunissa, Rao BS. 1975. Effect of protein level in the diet on quinolinate phosphoribosyltransferase of rat liver. Life Sci 15: 1597-1602.

2) Taguchi H, Iwai K. 1976. Inhibition of hog liver crystalline quinolinate phosphoribosyltransferase by nucleotides, quinolinate analogues and sulfhydryl reagents. Agric Biol Chem 40: 386-389.

3) Shibata K, Iwai K. 1980. Crystalline quinolinate phosphoribosyltransferase from hog kidney: Characteristic properties and chemical modifications. Agric Biol Chem 44: 293-300.

4) Shibata K, Murata K, Iwai K. 1980. Properties of quinolinate phosphoribosyltransferase from rat liver and kidney. Vitamins (Kyoto) 54: 171-175.

5) Shibata K, Iwai K. 1980. Crystalline quinolinate phosphoribosyltransferase from Alcaligenes eutrophus subsp. quinolinicus: Characteristic properties and chemical modifications. Agric Biol Chem 44: 287-292.

6) Marx JL. 1972. Phthalic acid esters: Biological impact uncertain. Science 178: 46-47.

7) Mayer F Jr, Stalling OL, Johnson JL. 1972. Phthalate es- ters as environmental contaminants. Nature 238: 411-413.

8) Albro PW, Thomas R, Fishbein L. 1973. Metabolism of diethylhexylphthalate by rats: Isolation and characterization of the urinary metabolites. J Chromatogr 76: 321-330.

9) Okada S, Tamemasa Y. 1978. Distribution and metabolism of di-(n-butyl)-phthalate in mice and its interaction with nucleic acids and proteins. Yakugaku 98: 1229-1235.

10) Shibata K, Motooka K, Murata K, Iwai K. 1982. Increase in growth rate and activity of the tryptophanNAD pathway caused by di- $n$-butylphthalate in rats fed on a tryptophan-limited diet. J Nutr Sci Vitaminol 28: 173-177.

11) Chang H-K, Zylstra GJ. 1999. Role of quinolinate phosphoribosyl transferase in degradation of phthalate by Burkholderia cepacia DBO1. J Bacteriol 181: 20693075.

12) Shibata K, Matsuo H. 1990. Effect of dietary tryptophan levels on the urinary excretion of nicotinamide and its metabolites in rats fed a niacin-free diet or a constant total protein level. J Nutr 120: 1191-1197.

13) Pullman ME, Colowick SP. 1954. Preparation of 2- and 6-pyridones of $N^{1}$-methylnicotinamide. J Biol Chem 206: 121-127.

14) Shibata K, Kawada T, Iwai K. 1988. Simultaneous micro-determination of nicotinamide and its major metabolites, $N^{1}$-methyl-2-pyridone-5-carboxamide and $N^{1}$-methyl-3-pyridone-4-carboxamide, by high-performance liquid chromatography. J Chromatogr 424: 23-28.

15) Shibata K, Fukuwatari T, Sugimoto E. 2000. Reversed phase HPLC of nicotinic acid mononucleotide for measurement of quinolinate phosphoribosyltransferase. J Chromatogr 749: 281-285.

16) Shibata K. 1987. Ultramicro-determination of $N^{1}$ methylnicotinamide in urine by high-performance liquid chromatography. Vitamins (Kyoto) 61: 599-604.

17) Walseth F, Toftgärd R, Nilsen OG. 1982. Phthalate esters I: Effects on cytochrome P-450 mediated metabolism in rat liver and lung, serum enzymatic activities and serum protein levels. Arch Toxicol 50: 1-10. 